\title{
How to Introduce the Cyclic Group and Its Properties Representation with Matlab? Thanks to Magic Using the Perfect Faro Shuffle
}

\author{
Pierre Schott \\ Art et Recherche NUMérique (ARNUM), Ecole Supérieure d’Informatique, d'Electronique et d'Automatisme (ESIEA), \\ Paris, France \\ Email: schott@esiea.fr, pierrot.schott@laposte.net, arnum@esiea-recherche.eu \\ Received July 21 $1^{\text {st }}$, 2010; revised February 21st, 2011; accepted February $23^{\text {rd }}, 2011$.
}

\begin{abstract}
Why use Magic for teaching arithmetic and geometric suit, additive groups, and algorithmic notions through Matlab? Magicians know that, once the surprise has worn off, the audience will seek to understand how the trick works. The aim of every teacher is to interest their students, and a magic trick will lead them to ask how? And why? And how can I create one myself? In this article we consider a project I presented in 2009. I summarize the project scope, the students' theoretical studies, their approach to this problem and their computer realizations. I conclude using the mathematical complement as well as weak and strong points of this approach. Whatever the student's professional ambitions, they will be able to see the impact that originality and creativity have when combined with an interest in one's work. The students know how to "perform" a magic trick for their family and friends, a trick that they will be able to explain and so enjoy a certain amount of success. Sharing a mathematical / informatics demonstration is not easy and that they do so means that they will have worked on understood and are capable of explaining this knowledge. Isn't this the aim of all teaching?
\end{abstract}

Keywords: Higher Education, Engineer, Educational Method

\section{Introduction}

I am fascinated by Magic (or rather conjuring!) and for many years I have used this way of teaching, both in my physics classes and as higher education teacher trainer.

I present all the notions in this paper, a brief history of Magic and finally I present the researchers who have used this Art to teach and/or to research.

The aim of the magician is to hide the principles he uses (using Maths, Physics, Psychology, sleight of hand, etc...) by disguising the trick so that the audience has no way of discovering how it is done thus allowing the Magic to remain.

The Teacher can do exactly the opposite: unraveling a magic trick to highlight the principles used!

\section{A Brief History of Magic}

From the beginning of time people have feared what they don't understand and sought logical explanations for inexplicable phenomena. To begin with they considered them to be the work of magic, then the work of the gods, then the work of God himself. The church discouraged the spread of the conjurer's art as it preferred not to have rational explanations for what was considered supernatural.

The first magic tricks were performed in the Middle Ages by clowns and/or con-men who would entertain passers-by by getting them to bet on the position of a ball hidden in one of three up-turned goblets, the bet being usually lost. This trick is known nowadays by the name 'cups and balls' (Mayol, 2000). The first book considered to be about modern Magic (or should we say "conjuring") was written and printed in the 16th Cen- tury. It was about Magic with ropes (Ammar, 1998). It wasn't until the end of the 19th Century that the word Magic took on its present-day meaning when the famous magician Houdini, father of modern Magic, made it the art it is today.

Since then a good number of principles have been invented and improved on by magicians and gamblers (Erdnase, 1902), especially for card tricks with bets. Since the 1980s the secrets that were once passed on from master to apprentice are now universally available through the use of video cassettes and modern communication technology, and Magic has become Big Business.

\section{Card Magic as the Vector of Research and Teaching}

From 1886 till 1896, Poincaré occupied the chair of probability Calculus" in the Paris university 'La Sorbonne'. He wrote a work named 'probability calculus' (Poincare, 1912; Sheynin, 1991) which was printed for the first time in 1896. In the second edition, he brings very fundamental new reflections on the groups and the hypercomplex systems and on the ergodic theory. He is brought to these innovations by the study of the card shuffling and liquids mixing. The problems of card shuffling and liquid diffusion studied by Poincaré are application cases of the ergodic theory which is in the center of the probability leveling phenomenon: if the deck was shuffled for a long time, all the possible permutations have the same probability.

Both principles of Gilbreath (Gilbreath, 1958; Gilbreath, 1966; Gilbreath, 1989) are fascinating principles, allowing to do extraordinary card tricks!

Some Mathematicians - such as M.Gardner (Magid, 2005; 
Gardner, 1958; Gardner, 2005), P.Diaconis (Diaconis, 1998; Diaconis, 2003; Assaf, 2009) or C.Mulcahy (Mulcahy, 2003; Mulcahy, 2004; Mulcahy, 2007)-, some computer specialists as G. Huet (Huet, 1991) one of creator of COQ language which allows to make automatic mathematical proof - studied this principle (and they are not the only ones !).

We shall not present this principle here but it is necessary to know that it is based on a commonly used card shuffles on both sides of the Atlantic Ocean: the American shuffle.

\section{Summary}

The subject was given for the 4th semester students in higher education school (named in France 'Grandes écoles d'ingénieurs'). The students had to solve and illustrate a fifty-year-old problem of Elmsley (Elmsley, 1957):

How to bring the original top card to position $p$ by perfect shuffles.

A theoretical solution is written in (Diaconis, 2006) by P. Diaconis and R. Graham.

By giving this project, I would like that the students:

- understand some mathematical notions as the cyclic group,

- learn a new useful programming language as Matlab ${ }^{\mathrm{TM}}$,

- discover a fascinating area and improve their creativity.

A deeper description of them is given in the third section. Having worked 4 months (part-time, that is approximately 75 hours per student or 300 hours for the whole project), the students have written Matlab ${ }^{\mathrm{TM}}$ functions and finally answered the subject requirements:

- find the number of Faro IN (or OUT) shuffles so that a card deck finds its initial order,

- find the Faro IN andlor OUT shuffle suit so that a card in position ' $k$ ' in the deck arrives in position 'j'.

Thus I explain the mathematical notions used as well as the associated equations which are resolved by the students Matlab functions!

\section{The Multi Disciplinary Project (M.D.P) of ESIEA in the French Higher Education}

We shall see successively the organization of higher education in France, the scope and the objectives of the M.D.P project.

\section{Higher Education in FRANCE}

In France, the secondary education is sanctioned by the high school diploma. Ideally the pupils obtain it at the age of 18 . Then, they have a plethora of possibilities following 3 orientations:

- Some undertake short studies called "professional" in an I.U.T at the University or in high school with the aim of obtaining a BTS. Both programs lead to a 2-year technical degree,

- Others undertake longer studies. In this case, if they have obtained their high school diploma they can:

1) Enrol in university,

2) Or enter preparatory courses (classes for entrance into 'Grandes Ecoles') for 2 years, which will lead them, via national entrance examinations, to enter a 'Grande Ecole' in business or engineering.

The studies take 3 years and once they have their degree in hand, the students find employment easily.

The school in which I work, named E.S.I.E.A, is an engineering school.

\section{The Scopes of the M.D. P. Project}

The M.D.P. is a 4th semester project, taking place between February and May (75 homework hours are planned for each student) and students are organized into groups of 4 . Their work is closely followed by a professor. Because the project is to be developed during the students' free time, they also take other courses during this semester.

The subjects can be of three kinds:

- 'Professional' subjects requested directly by the partner companies of the school,

- 'Research' subjects given by research centers,

- 'Educational' subjects proposed by the school's professors.

The subjects are collected by the school administration, communicated to the students and finally 3 subjects are chosen by each 4-student group. Through an internal process, the students are assigned a subject (most frequently their first request).

\section{The M.D.P Educational Objectives}

The main objective is to apply to a project the knowledge acquired during coursework, and if need be, to enrich this knowledge.

A second objective is to raise students' awareness that a project is not reduced to a single academic subject but is in fact a conglomerate of knowledge taught in various courses.

Finally, let us note the importance of project management among these objectives.

An extract of the program is given in appendix A.

\section{The Assigned M.D.P}

The contents of a project I assigned to a group of students, the motivations and my expectations are described below.

Diaconis has entirely solved this subject in (Diaconis, 1983) ... but I think it's unreadable by the students ... and me !

\section{The Proposed Subject in 2009-2010}

The magic arts consist of several specialties: close - up, cups and balls, coin tricks, transformists, card tricks, and so on ... The most mediatized specialty, enjoyed by all kinds of audience, is: the Grand Illusion. But the easiest is self-working card tricks.

In fact, many magic tricks are based on mathematical notions. The art of the magician consists in the fact that the spectators do not realize it!

The Faro shuffle (which is a particular case of the American shuffle) admits many properties; in particular the one which consists in making 8 Faro shuffles from a new 52 cards deck and the deck returns to its initial order!

We propose you:

- To demonstrate this property mathematically and by computer.

- To generalize this principle: to define in advance (Thanks to mathematical equations) or after (thanks to the computer) 
how much IN (or OUT) Faro shuffles are necessary so that an $\mathrm{N}=2 \mathrm{p}$ card deck returns to its initial order.

- To determine how many IN and/or OUT Faro shuffle suit are necessary so that a card in ' $\mathrm{k}$ ' position in the $\mathrm{N}=2 \mathrm{p}$ card deck arrives in 'j' position.

- To use the previous results to create a magic trick.

- To create a Human-Machine Interface (HMI) which allows displaying step by step -with cards- the mathematical demonstrations.

If you want to know the secrets of the greatest magicians, come!

If you want to learn and apply mathematical and informatics theory in a fun way, come!

ATTENTION: once the secret is known, the illusion loses all its magic ... but not its spectacular beauty!

\section{My Motivations to Propose such a Subject}

I chose the topic of magic, a subject which fascinates me, to be virtually certain that the topic would be completely new for the students. So they are in an unfamiliar situation. They will thus have to implement all the necessary means to complete the project successfully.

I also try to arouse the students' curiosity by proposing a subject that is more playful than usual.

Following these objectives, I propose a project in informatics and math analysis (in cyclic groups), while the school in which I work hardly teaches this subject. I go out very slightly of the project scope because once in a company, the students will have to study - or to solve - problems that they have never seen during their academic career.

Consequently, the students have to look for, find and understand a 'new' theory of mathematics and new software: Matlab.

After all I give them work that is more difficult than that expected by the school. Indeed there is little chance that I will have a student, who is the son or daughter of a magician or who is a magician himself.

Finally, I try to change the traditional way of teaching: a downward method (the professor teaches the student) usually used in France, become an ascending method here (it is the student who will have to explain to the professor).

The ascending method has the merit of showing whether the problem posed is well understood. As Boileau wrote (Boileau, 1740) "what is well conceived expresses itself clearly, and the words to say it come easily” (“ce qui se conçoit bien s'énonce clairement, et les mots pour le dire arrivent aisément”).

\section{My Expectations}

I thus expect from my students:

1) That they perform research on different magic shuffles (American, Faro, Zarrow ...) and their associated properties.

2) That they perform research in mathematics:

a) properties of divisibility and associated equations,

b) cyclic groups,

3) That they perform research in informatics:

a) programming with Matlab,

b) representing with 2D-3D Matlab's figures,

4) That they model well the 'magic' problem.

5) That the realization of a card trick based on the Faro properties is interesting from both angles: magic and mathematics.

Finally its presentation during the viva must be well orga- nized and as magic as possible.

\section{The Group Composition}

Table 1 specifies the capacities of a student having followed our engineering school program, at the beginning of the M.D. Project:

- The group consisted of 3 students. Their initial level is 'above average' according to the standards of evaluation used in France.

- The first one had been interested, thanks to extra school activities, to the website design using databases. This student is rather classified at the top of class (Having A- to B in the Anglo-Saxon system).

- The second one is a hard-working student. Thanks to it, he manages to validate all modules with notes included between (B- to D+).

The third one asks a lot of good questions -which are often out of the teaching program. But he doesn't manage to be clear in his' mind on a given theme. So his notes are dissimilar.Tous trois sont

\section{The Theoretical Part of the Student's Realization}

Before solving the problem, it is clearly necessary to define Faro and American shuffles for example. It is also necessary to know how the cards could be informatics represented.

\section{Card Deck Representation}

Some important definitions, shown on Figure 1:

- The card is called face up if everyone can see the value (from Ace to King) and the color (club - diamond - spade heart).

- The card is called face down if no one can see the value (from Ace to King) and the color (club - diamond - spade heart).

A card deck is the superimposing of several cards. To simplify, either all the cards are face up, or face down. The current card value (resp. color) abbreviations included in Table 2 (resp. 3) are used here.

To end, let us use the following example: 1C-4D-QS-KH-10D-3C-JD-4S-10H

Table 1.

Initial students' leval according to my expectations.

\begin{tabular}{|c|c|c|}
\hline & $\begin{array}{l}\text { Expected objectives } \\
\text { Magic documentation }\end{array}$ & $\begin{array}{c}\text { Students' initial level } \\
\text { None is magician }\end{array}$ \\
\hline \multirow{2}{*}{$\begin{array}{l}\text { Research in } \\
\text { mathematics }\end{array}$} & Properties of divisbility & $\begin{array}{c}\text { They had a course on } \\
\text { this subject and obtained } \\
\text { a C }\end{array}$ \\
\hline & Cyclic group & $\begin{array}{l}\text { Only explained at the } \\
\text { end of the algebra course } \\
\text { Have never written a }\end{array}$ \\
\hline \multirow{4}{*}{$\begin{array}{l}\text { Research in } \\
\text { informatics }\end{array}$} & Programming with & Matlab program but had \\
\hline & Matlab & $\begin{array}{c}3 \text { semesters C language } \\
\text { course }\end{array}$ \\
\hline & $\begin{array}{l}\text { Representing with 2D } \\
\text { Matlab figures }\end{array}$ & $\begin{array}{l}\text { Had never use graphic } \\
\text { tools library. }\end{array}$ \\
\hline & Modelisation & $\begin{array}{l}\text { Insufficient in mathe- } \\
\text { matics and average for } \\
\text { computing using } C \text {. }\end{array}$ \\
\hline
\end{tabular}




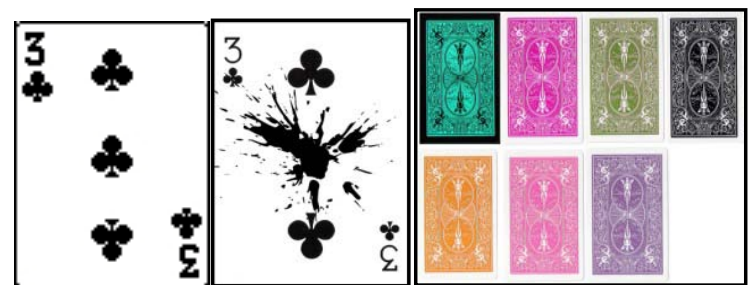

Figure 1.

Face up cards (left and center) and face down card (right).

The first card is the Ace of clubs and the last one is the 10 of hearts. Two configurations are evadible:

- The cards are face down and, when the deck is face down too, the order is the same (thus the first card is the Ace of clubs and the last one is the 10 of hearts), as shown on Figure 2.

The cards are face down and, when the deck is face down too, the order is the same (thus the first card is the 10 of hearts and the last one is the Ace of clubs), as shown on Figure 3.

\section{The American Shuffle}

Let's consider an $\mathrm{N}$ card deck cut in two equal parts (or almost) as shown on Figure 4.

To shuffle a deck in the American way, each card held in right hand (for example) must be inserted in the deck held in left hand. The number of cards inserted as well as the position (for every insertion) is totally random, as presented on Figure 7.

\section{The Faro Shuffle (or the Pharaoh Shuffle)}

Let us consider a deck cut in two subdeck named C and D as shown before. The Faro shuffle is a particular American shuffle. Each card from one subdeck is inserted in the second subdeck between two different suitable cards (and conversely!).

The OUT (resp. IN) Faro shuffle begins with the top card of the C-deck (resp. D-deck) as presented on Figure 6 (resp. 7).

What is remarkable is that only for the OUT Faro shuffle; two cards always stay in their initial position (the first and the last card).

Table 2.

Used Abbreviations for the cards values.

\begin{tabular}{|c|c|c|c|c|c|c|c|c|c|c|c|c|c|}
\hline Value & $\ddot{\&}$ & 2 & 3 & 4 & 5 & 6 & 7 & 8 & 9 & 10 & $\underset{\tilde{J}}{\stackrel{y}{\tilde{J}}}$ & $\begin{array}{l}\tilde{\Xi} \\
\Xi \\
\Xi\end{array}$ & $\stackrel{0}{0}$ \\
\hline $\begin{array}{c}\text { Ab- } \\
\text { brevia- } \\
\text { tion }\end{array}$ & 1 & 2 & 3 & 4 & 5 & 6 & 7 & 8 & 9 & 10 & $\mathrm{~J}$ & $\mathrm{Q}$ & $\mathrm{K}$ \\
\hline
\end{tabular}

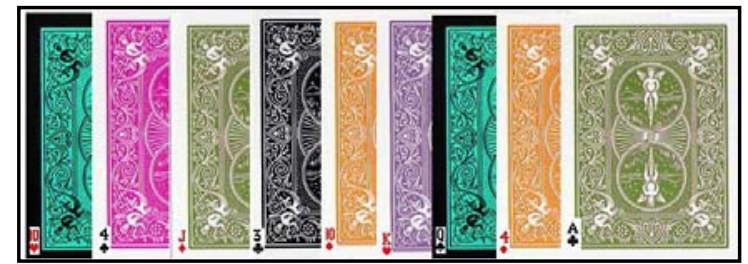

Figure 2.

An example of a cards deck (face down) : [1C-4D-QS-KH-10D$3 C-J D-4 S-10 H]$.
Table 3.

Abbreviations used for the card colors.

\begin{tabular}{ccccc}
\hline Color & Club & Diamond & Spade & Heart \\
\hline Abbreviation & $\mathrm{C}$ & $\mathrm{D}$ & $\mathrm{S}$ & $\mathrm{H}$ \\
\hline
\end{tabular}

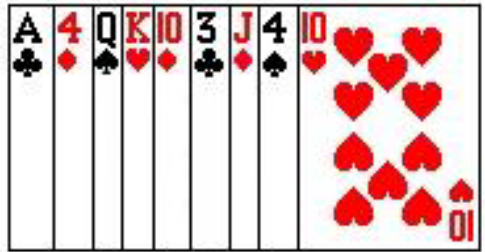

Figure 3.

The same example as figure 2 face up: [1C-4D-QS-KH-10D-3C-JD-4S-10H].

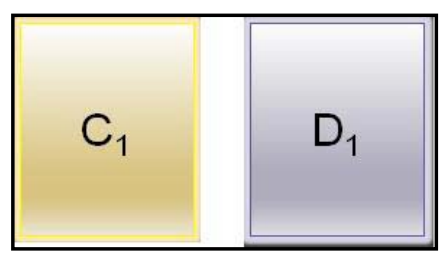

Figure 4.

$N$ card deck cut in two (almost) equal part.

\begin{tabular}{llllllllllllll}
$\mathrm{C}_{1}$ & $\mathrm{C}_{2}$ & $\mathrm{D}_{1}$ & $\mathrm{D}_{2}$ & $\mathrm{C}_{3}$ & $\mathrm{D}_{3}$ & $\mathrm{D}_{4}$ & $\mathrm{D}_{5}$ & $\mathrm{C}_{4}$ & $\mathrm{C}_{5}$ & $\ldots$ & $\mathrm{C}_{\mathrm{a}}$ & $\mathrm{D}_{\mathrm{max}}$ & $\mathrm{D}_{(n+1}$ \\
\hline
\end{tabular}

Figure 5.

Shuffled deck by the American way.

\section{The IN and OUT Faro Shuffle with a New Card Deck}

A new deck is in the order as shown on Figure 8.

The deck is cut exactly in two equal 26 card parts. The first deck is held in the right hand (for example) and the second in the left hand, as shown on Figure 9.

In Figure 10 (resp. 11) the result of a new deck OUT (resp. IN) faro shuffle is presented.

The initial and final positions of each club (resp. diamond spade - heart) card is given in Table 4 (resp. 5 - 6 - 7) for an IN or OUT Faro shuffle.

Let us remark the following property for an OUT faro shuffle: the final position $(\mathrm{pn}+1)$ of a card belonging to the 26 first (resp. last) cards deck is obtained by multiplying by 2 the initial position (pn) (modulo 52) less 1 (resp. 0) ; the following equation is also obtained :

$$
\mathrm{p}_{\mathrm{n}+1}=2 \mathrm{p}_{\mathrm{n}}-1 \text { [52] or } \mathrm{p}_{\mathrm{n}+1}=2 \mathrm{p}_{\mathrm{n}} \text { [52] }
$$

Let us remark the following property for an IN faro shuffle: the final position $\left(\mathrm{p}_{\mathrm{n}+1}\right)$ of a card belonging to the 26 first (resp. last) cards deck is obtained by multiplying by 2 the initial position $\left(\mathrm{p}_{\mathrm{n}}\right)$ (modulo 52) less 0 (resp. 1 ) ; the following equation is also obtained :

$$
p_{n+1}=2 p_{n}[52] p_{n}+1=2 p_{n}-1[52]
$$




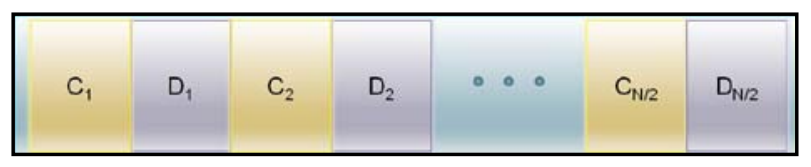

Figure 6.

The OUT Faro Shuffle of a $N$ cards deck.

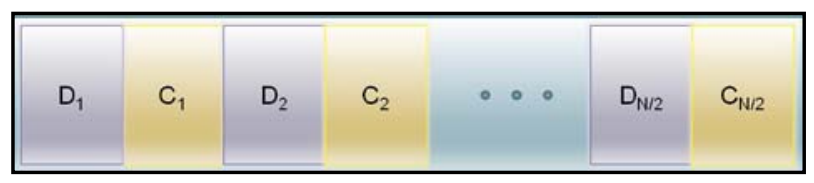

Figure 7.

The IN Faro Shuffle of a $N$ cards deck.

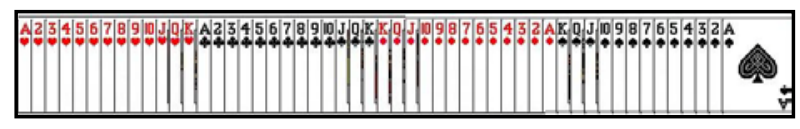

Figure 8.

A New card deck with the bicycle ${ }^{T M}$ order.

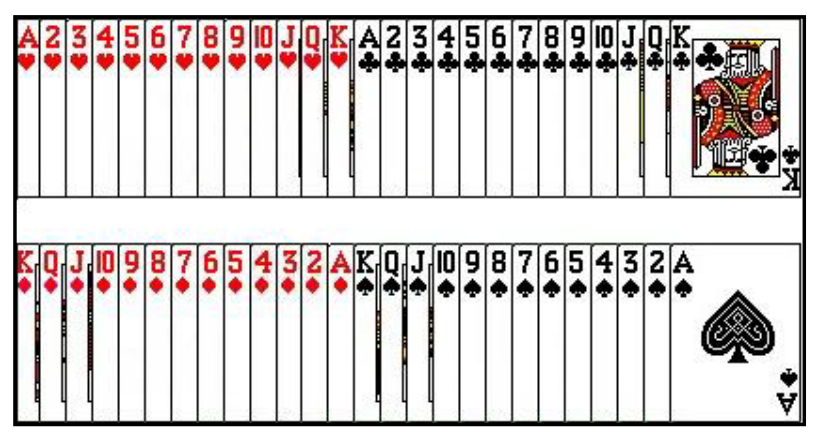

Figure 9.

A New card deck with the bicycle ${ }^{T M}$ order cut in two halves.

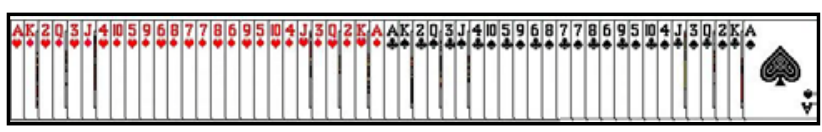

Figure 10.

The OUT faro shuffle from a new card deck with the the bicycle ${ }^{T M}$ order.

Table 4.

The initial positions of each club card and their positions after an IN or OUT Faro shuffle.

\begin{tabular}{cccccccccccccc}
\hline Clubs & 1 & 2 & 3 & 4 & 5 & 6 & 7 & 8 & 9 & 1 & $\mathrm{~J}$ & $\mathrm{Q}$ & $\mathrm{K}$ \\
\hline \multirow{3}{*}{ Initial } & 1 & 1 & 1 & 1 & 1 & 1 & 2 & 2 & 2 & 2 & 2 & 2 & 2 \\
& 4 & 5 & 6 & 7 & 8 & 9 & 0 & 1 & 2 & 3 & 4 & 5 & 6 \\
& & & & & & & & & & & & & \\
Faro & 2 & 2 & 3 & 3 & 3 & 3 & 3 & 4 & 4 & 4 & 4 & 4 & 5 \\
OUT & 7 & 9 & 1 & 3 & 5 & 7 & 9 & 1 & 3 & 5 & 7 & 9 & 1 \\
& & & & & & & & & & & & & \\
Faro & 2 & 3 & 3 & 3 & 3 & 3 & 4 & 4 & 4 & 4 & 4 & 5 & 5 \\
IN & 8 & 0 & 2 & 4 & 6 & 8 & 0 & 2 & 4 & 6 & 8 & 0 & 2 \\
\hline
\end{tabular}

Table 5.

The initial positions of each diamond card and their positions after an IN or OUT Faro shuffle.

\begin{tabular}{cccccccccccccc}
\hline Diamond & $\mathrm{K}$ & $\mathrm{Q}$ & $\mathrm{J}$ & $\begin{array}{c}1 \\
0\end{array}$ & 9 & 8 & 7 & 6 & 5 & 4 & 3 & 2 & 1 \\
\hline Initial & 27 & 2 & 2 & 3 & 3 & 3 & 3 & 3 & 3 & 3 & 3 & 3 & 3 \\
& & 8 & 9 & 0 & 1 & 2 & 3 & 4 & 5 & 6 & 7 & 8 & 9 \\
Faro & & & & & & & & & & & & & \\
OUT & 2 & 4 & 6 & 8 & 1 & 1 & 1 & 1 & 1 & 2 & 2 & 2 & 2 \\
& & & & & & 2 & 4 & 6 & 8 & 0 & 2 & 4 & 6 \\
Faro & 1 & 3 & 5 & 7 & 9 & 1 & 1 & 1 & 1 & 1 & 2 & 2 & 2 \\
IN & 1 & 3 & & & & 1 & 3 & 5 & 7 & 9 & 1 & 3 & 5 \\
\hline
\end{tabular}

Table 6.

The initial positions of each club card and their positions after an IN or OUT Faro shuffle.

\begin{tabular}{cccccccccccccc}
\hline \multirow{2}{*}{ Spade } & $\mathrm{K}$ & $\mathrm{Q}$ & $\mathrm{J}$ & 1 & 9 & 8 & 7 & 6 & 5 & 4 & 3 & 2 & 1 \\
& & & & 0 & & & & & & & & & \\
\hline \multirow{2}{*}{ Initial } & 4 & 4 & 4 & 4 & 4 & 4 & 4 & 4 & 4 & 4 & 5 & 5 & 5 \\
& 0 & 1 & 2 & 3 & 4 & 5 & 6 & 7 & 8 & 9 & 0 & 1 & 2 \\
& & & & & & & & & & & & & \\
Faro & 2 & 3 & 3 & 3 & 3 & 3 & 4 & 4 & 4 & 4 & 4 & 5 & 5 \\
OUT & 8 & 0 & 2 & 4 & 6 & 8 & 0 & 2 & 4 & 6 & 8 & 0 & 2 \\
& & & & & & & & & & & & & \\
Faro & 2 & 2 & 3 & 3 & 3 & 3 & 3 & 4 & 4 & 4 & 4 & 4 & 5 \\
IN & 7 & 9 & 1 & 3 & 5 & 7 & 9 & 1 & 3 & 5 & 7 & 9 & 1 \\
\hline
\end{tabular}

Table 7.

The initial positions of each heart card and their positions after an IN or OUT Faro shuffle.

\begin{tabular}{llllllllllllll}
\hline Heart & 1 & 2 & 3 & 4 & 5 & 6 & 7 & 8 & 9 & 1 & $\mathrm{~J}$ & $\mathrm{Q}$ & $\mathrm{K}$ \\
& & & & & & & & & & 0 & & & \\
\hline Initiale & 1 & 2 & 3 & 4 & 5 & 6 & 7 & 8 & 9 & 1 & 1 & 1 & 1 \\
& & & & & & & & & & 0 & 1 & 2 & 3 \\
Faro & 1 & 3 & 5 & 7 & 9 & 1 & 1 & 1 & 1 & 1 & 2 & 2 & 2 \\
OUT & & & & & & 1 & 3 & 5 & 7 & 9 & 1 & 3 & 5 \\
& & & & & & & & & & & & & \\
Faro & 2 & 4 & 6 & 8 & 1 & 1 & 1 & 1 & 1 & 2 & 2 & 2 & 2 \\
IN & & & & & 0 & 2 & 4 & 6 & 8 & 0 & 2 & 4 & 6 \\
\hline
\end{tabular}

\section{OUT Faro Shuffle and Nothing is done!}

Armed with these results, the students have been able to verify the following properly : if a card deck is 8 times In Faro shuffled, then the deck is in its initial order !

- The demonstration is proposed in appendix B for a deck.

- The visualization is proposed below -obtained by informatics Matlab ${ }^{\mathrm{TM}}$ function given in appendix C)

" Initially, the card deck is in the following order (presented on Figure 12):

By cutting the deck between both Kings and after an OUT Faro Shuffle, the card deck is in the following order (presented on Figure 13):

By cutting the deck between both Aces and after an OUT Faro Shuffle, the card deck is in the following order (presented on Figure 14): 
By cutting the deck between both 7s (club and diamond) and after an OUT Faro Shuffle, the card deck is in the following order (presented on Figure 15):

By cutting the deck between both 4 s (club and diamond) and after an OUT Faro Shuffle, the card deck is in the following order (presented on Figure 16):

By cutting the deck between both 9s (spade and heart and after an OUT Faro Shuffle, the card deck is in the following order (presented on Figure 17):

By cutting the deck between both 5 s (spade and heart and after an OUT Faro Shuffle, the card deck is in the following order (presented on Figure 18):

By cutting the deck between both 3s (spade and heart and after an OUT Faro Shuffle, the card deck is in the following order (presented on Figure 19):

By cutting the deck between both 2s (club and diamond) and after an IN Faro Shuffle, the card deck order is the initial one (presented on Figure 12).'’(Chardiny, 2010).

The demonstration is proposed in appendix B for a deck.

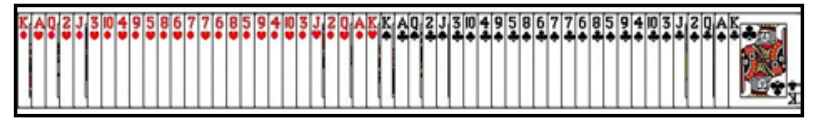

Figure 11.

The IN faro shuffle from a new card deck with the the bicycle ${ }^{T M}$ order.

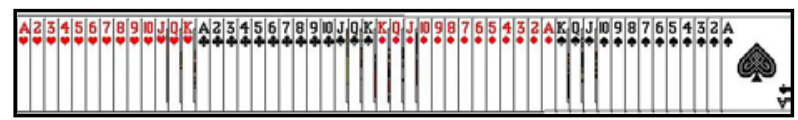

Figure 12.

A new (bicycle ${ }^{T M}$ ) card deck.

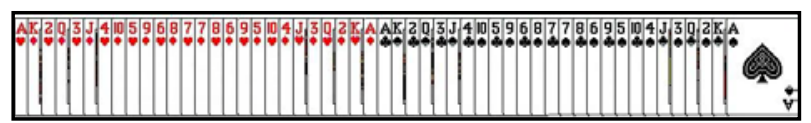

Figure 13.

A new (bicycle ${ }^{T M}$ ) card deck after one OUT Faro shuffle.

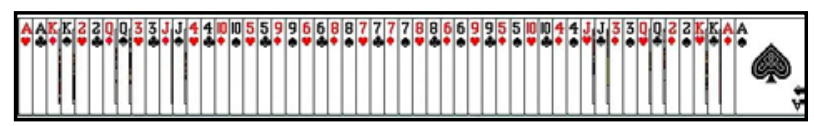

Figure 14.

A new (bicycle ${ }^{T M}$ ) card deck after two OUT Faro shuffle.

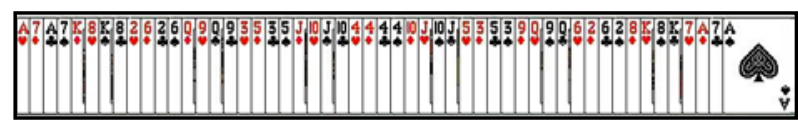

Figure 15.

A new (bicycle ${ }^{T M}$ ) card deck after three OUT Faro shuffle.

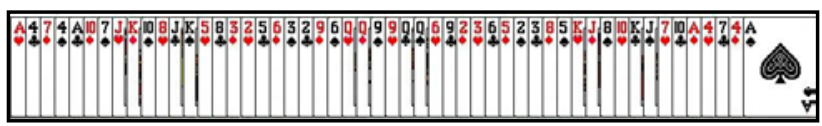

Figure 16.

A new (bicycle ${ }^{T M}$ ) card deck after four OUT Faro shuffle.

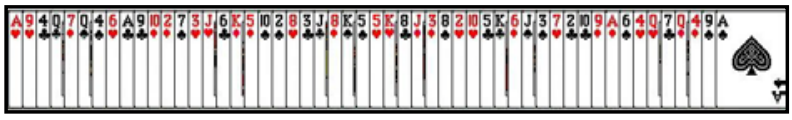

Figure 17.

A new (bicycle ${ }^{T M}$ ) card deck after five OUT Faro shuffle.

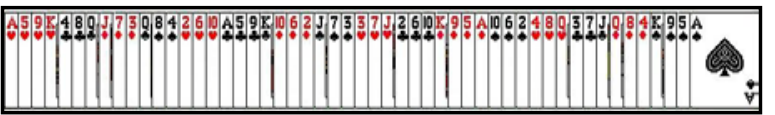

Figure 18.

A new (bicycle ${ }^{T M}$ ) card deck after six OUT Faro shuffle.

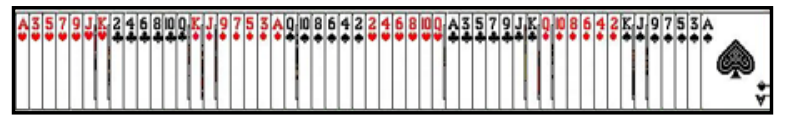

Figure 19.

A new (bicycle ${ }^{T M}$ ) card deck after seven OUT Faro shuffle.

\section{The Informatics Part of the Student's Realization}

The students had the following aim; to answer both questions:

- find the number of Faro IN (or OUT) shuffles so that a card deck finds its initial order,

- find the Faro IN and \or OUT shuffle suit so that a card in position ' $k$ ' in the deck arrives in position 'j'.

The students answered both these questions simply by using the function 'faro_function' (described in appendix C).

How many Faro shuffles (IN or OUT) are necessary in order to find the initial order of a deck of $\mathrm{N}=2 \mathrm{p}$ cards?

To answer this question, the students simply made a 'while' loop with the condition: the vector representing the card deck after ' $k$ ' IN (or OUT) shuffles is identical to the initial vector representing the initial card deck.

The results are given on Figure 20 where we have:

- in the X-axis the number of cards in the initial deck,

- in the Y-axis the number of successive shuffles it is necessary to do so that the deck returns to its initial order.

Two curves are drawn (one for the IN Faro shuffle and the other one for the OUT). The third represents the first bisector.

We notice that with a series of OUT Faro Shuffles, it is always possible to find a shuffle number lower than the card deck number to realize the property (contrary to the IN Faro shuffle!).

What succession of IN and OUT shuffles is necessary so that a card in position $\mathrm{j}$ is to be found in position $\mathrm{k}$ in a deck of $\mathrm{N}=$ 2p cards?

Typically to solve this problem, it is necessary to make a tree by computer.

In Figure 21 we propose, a tree for:

- an initial 16 card deck $(\mathrm{p}=8$ ),

- the initial position for the selected card is the top (the first card has the position 0 ).

- To find the successive shuffles needed in order for the selected card to be in the fourth position (equivalence class 3) will be:

- in position 8 : only one IN shuffle, 


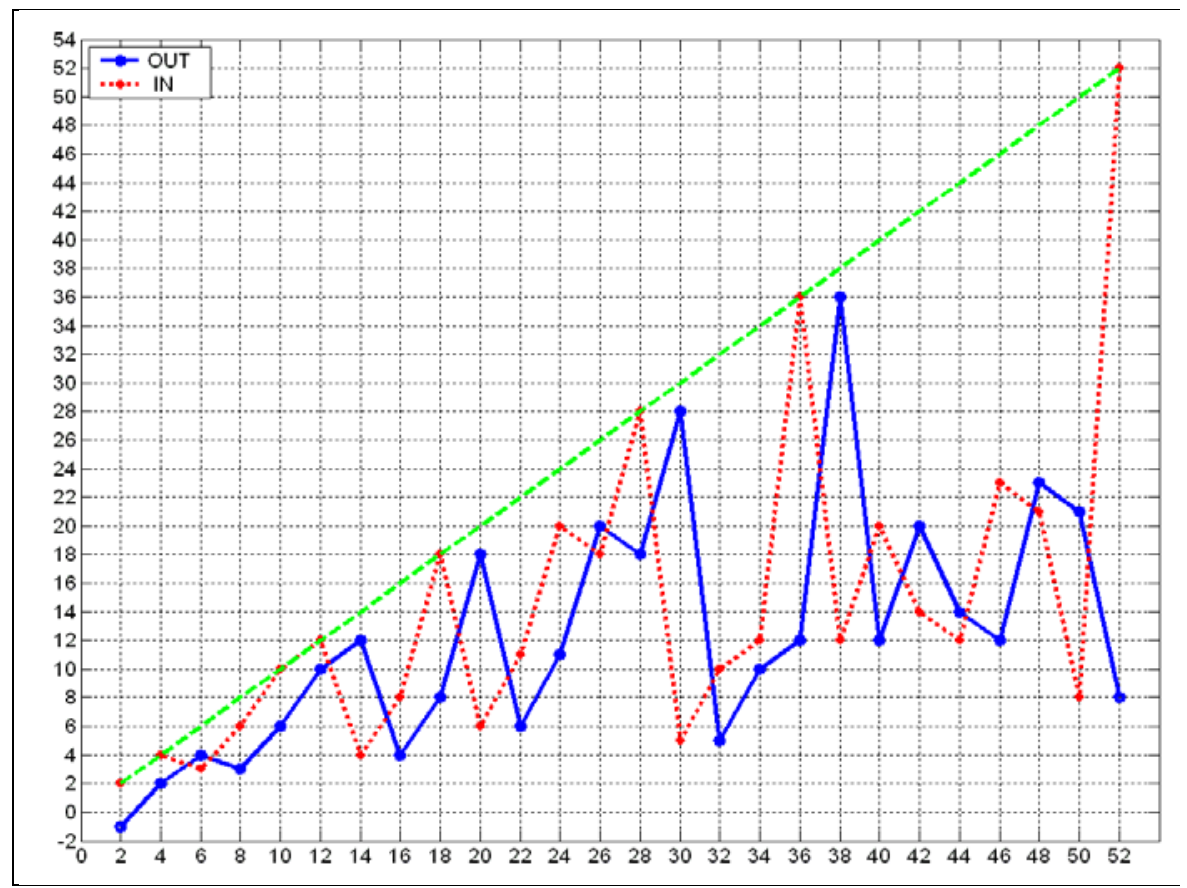

Figure 20.

Number of successive shuffles needed in order to a card deck return to its initial position versus the number of card deck.

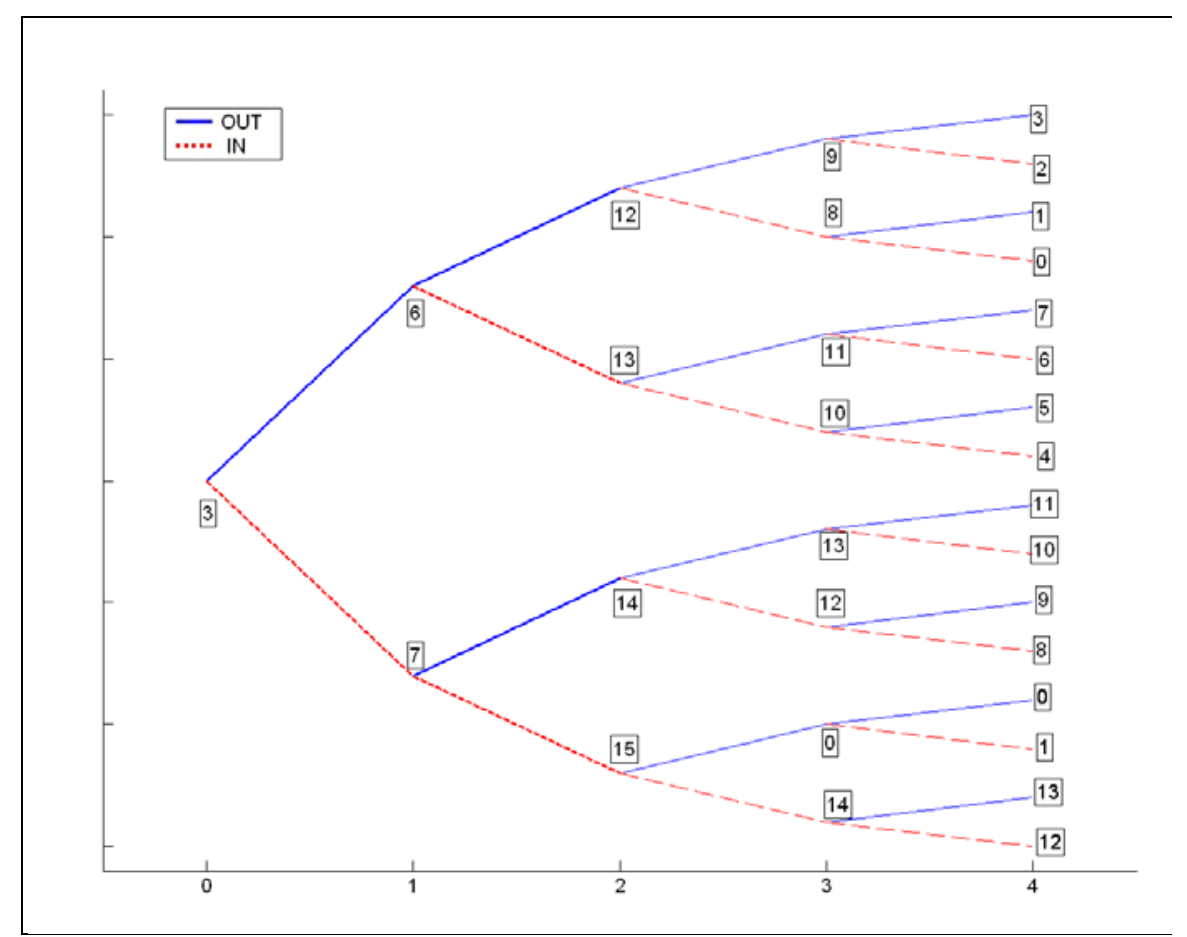

Figure 21.

Tree of successive IN and/or OUT Faro Shuffle for a 16 card deck.

- in position 7 : only one OUT shuffle,

- in position 15: an IN shuffle then an OUT one or 3 IN shuffles (there is not only one solution !),
- at the top of the deck (first position):

1) 2 OUT shuffles then 2 IN shuffles,

2) 2 IN shuffles then 1 OUT shuffle, 


\section{The Notions - Which I Gave-Can be the Summary of a Maths Course on the Cyclic Groups}

The students found the laws for the OUT (resp. IN) shuffles written in the equation 1) (resp. 2). Now these equations must be written in a unique equation which could allow us to solve both problems.

It is then necessary to use the equivalence classes (thus to work in $\mathrm{Z} / \mathrm{mZ}$ ) which represent the possible positions of cards. They are between 0 and (m-1) for associated positions between 1 and $\mathrm{m}$.

I thus give the new relations governing IN and OUT shuffles as well as the equations to be resolved in order to solve the both proposed questions which were solved by computer by the students.

\section{The New Equations for the IN and OUT Faro Shuffle}

Let us illustrate the results for the OUT (resp. IN) Faro shuffle given by the equation (1) (resp. 2); let us note the possible positions of cards for a $\mathrm{N}=2 \mathrm{p}$ deck. The results are shown in Table 8.

For the OUT (resp. IN) Faro shuffle, the final position of the ' $\mathrm{p}-1$ ' first cards from the top follows the equation ' $2 \mathrm{k}$ ' (resp. ' $2 \mathrm{k}+1$ ').

The transition is between the ' $p-1$ ' term and the ' $p$ ' term. If we use the same relation as before, we obtain the value '2p' (resp. ' $2 p^{+1}$ '). But we have to obtain the value 1 (resp. 0 ).

So the modulo to use is for the OUT (resp. IN) Faro shuffle '2p-1' (resp. '2p+1'). The new relations are given to the equation (3) (resp. 4):

$$
\begin{gathered}
\mathrm{p}_{\mathrm{k}+1} \equiv 2 \mathrm{p}_{\mathrm{k}}[2 \mathrm{p}-1] \\
\mathrm{p}_{\mathrm{k}+1} \equiv 2 \mathrm{p}_{\mathrm{k}}+1[2 \mathrm{p}+1]
\end{gathered}
$$

The card deck returns to its initial order if the card in the initial position $\mathrm{k}=\mathrm{p}_{0}$, after $\mathrm{m}$ Faro shuffles of a $\mathrm{N}=2 \mathrm{p}$ card deck, returns to its position $\mathrm{k}=\mathrm{p}_{\mathrm{m}}$, where $\mathrm{p}_{\mathrm{i}}$ is the position of this considered card at the ith shuffle.

Table 8 .

What happens to the position of each card of a $2 p$ card deck AFTER an IN or an OUT Faro shuffle?

\begin{tabular}{cccc}
\hline Initial positions & & $\begin{array}{c}\text { After an } \\
\text { OUT-shuffle }\end{array}$ & After an IN-shuffle \\
\hline 0 & $\rightarrow$ & 0 & 1 \\
1 & $\rightarrow$ & 2 & 3 \\
2 & $\rightarrow$ & 4 & 5 \\
$\therefore$ & $\therefore$ & $\therefore$ & $\therefore$ \\
$\mathrm{p}-1$ & $\rightarrow$ & $2 \mathrm{p}-2$ & $2 \mathrm{p}-1$ \\
$\mathrm{p}$ & $\rightarrow$ & 1 & 0 \\
$\mathrm{p}+1$ & $\rightarrow$ & 3 & 2 \\
$\therefore$ & $\therefore$ & $\therefore$ & $\therefore$ \\
$2 \mathrm{p}-2$ & $\rightarrow$ & $2 \mathrm{p}-3$ & $2 \mathrm{p}-4$ \\
$2 \mathrm{p}-1$ & $\rightarrow$ & $2 \mathrm{p}-1$ & $2 \mathrm{p}-2$ \\
\hline
\end{tabular}

For that purpose, it is necessary to solve, for each of both cases, the following equation:

$$
\mathrm{p}_{\mathrm{m}} \equiv \mathrm{p}_{0}[2 \mathrm{p}-1](\text { OUT }) \text { or } \mathrm{p}_{\mathrm{m}} \equiv \mathrm{p}_{0}[2 \mathrm{p}+1](\mathrm{IN})
$$

For the OUT faro shuffle, it occurs that:

$$
\mathrm{p}_{\mathrm{m}} \equiv 2^{\mathrm{m}} \mathrm{p}_{0}[2 \mathrm{p}-1]
$$

For the IN faro shuffle, it occurs that:

$$
\mathrm{p}_{\mathrm{m}} \equiv 2^{\mathrm{m}} \mathrm{p}_{0}+2^{\mathrm{m}}-1[2 \mathrm{p}+1]
$$

The demonstration can be made by recurrence.

\section{The OUT Faro shuffle}

The equation (6) becomes:

$$
2^{\mathrm{m}} \mathrm{k} \equiv \mathrm{k}[2 \mathrm{n}-1] \Leftrightarrow 2^{\mathrm{m}} \equiv 1[2 \mathrm{p}-1]
$$

This equation is solvable for ' $\mathrm{m}$ ' if $\mathrm{p}$ is given. When $\mathrm{p}$ varies from 1 to 26, the Figure 20 is also obtained (by calculating only powers of 2 !).

Let us take the most classic case -a 52 card deck- Thus $2 \mathrm{p}=$ 52 , and $2 p-1=51=17 * 3$. So by the theorem of Euler-Fermat, we know that there are 16 numbers which divide the class 51 . Let us then try the values of $2 \mathrm{j}$ until we find the value of $\mathrm{m}$ :

$$
\begin{aligned}
& 2^{1} \equiv 2[51] ; 2^{2} \equiv 4[51] ; 2^{3} \equiv 8[51] ; 2^{4} \equiv 16[51] \\
& 2^{5} \equiv 32[51] ; 2^{6} \equiv 13[51] ; 2^{7} \equiv 26[51] ; 2^{8} \equiv 1[51]
\end{aligned}
$$

So, effectively 8 OUT Faro shuffles are needed in order for a shuffled deck to return to its initial order!

By storing the successive values of $2 \mathrm{j}$ [51], we have the successive classes taken by the initial card at the position 1 (class 0 ) in the deck. Figure 22 presents these values given by the Equations (9) and (10) as well as their order of appearance.

IN shuffle

The Equation (7) becomes:

$$
2^{\mathrm{m}} \mathrm{k}+2^{\mathrm{m}}-1 \equiv \mathrm{k}[2 \mathrm{p}+1] \Leftrightarrow 2^{\mathrm{m}} \equiv 1[2 \mathrm{p}+1]
$$

This equation is solvable for ' $\mathrm{m}$ ' if $\mathrm{p}$ is given. When $\mathrm{p}$ varies from 1 to 26, figure 20 is also obtained (by calculating only powers of 2 !).

Let us take the most classic case -a 52 card deck- Thus $2 \mathrm{p}=$ 52 , and $2 p+1=53$ which is a prime number ! So by the theorem of Euler-Fermat, we know that there are 52 numbers which divide the class 53 . Let us try then the values of $2 \mathrm{j}$ until find the value of $\mathrm{m}$ :

$$
\begin{gathered}
2^{1} \equiv 2[53] ; 2^{2} \equiv 4[53] ; 2^{3} \equiv 8[53] ; 2^{4} \equiv 16[53] \\
2^{5} \equiv 32[53] ; 2^{6} \equiv 11[53] ; 2^{7} \equiv 22[53] ; 2^{8} \equiv 48[53]
\end{gathered}
$$

And so on ... effectively 53 IN Faro shuffles are needed in order for a shuffle deck to return to its initial order -as we can read on Figure 20!

By storing the successive values of $2 \mathrm{j}$ [51], we have the successive classes taken by the initial card at the position 1 (class 0 ) in the deck. Figure 23 presents these values given by the Equations (12) and (13) as well as their order of appearance.

We notice that all the classes are thus affected. We can conclude that 2 is generative of the multiplicative group.

What succession of IN and OUT shuffles is necessary so that a card in position $\mathrm{j}$ is to be found in position $\mathrm{k}$ in a deck of $\mathrm{N}=$ $2 \mathrm{p}$

Diaconis gave the following lemma to answer this question when $\mathrm{j}=0$. 


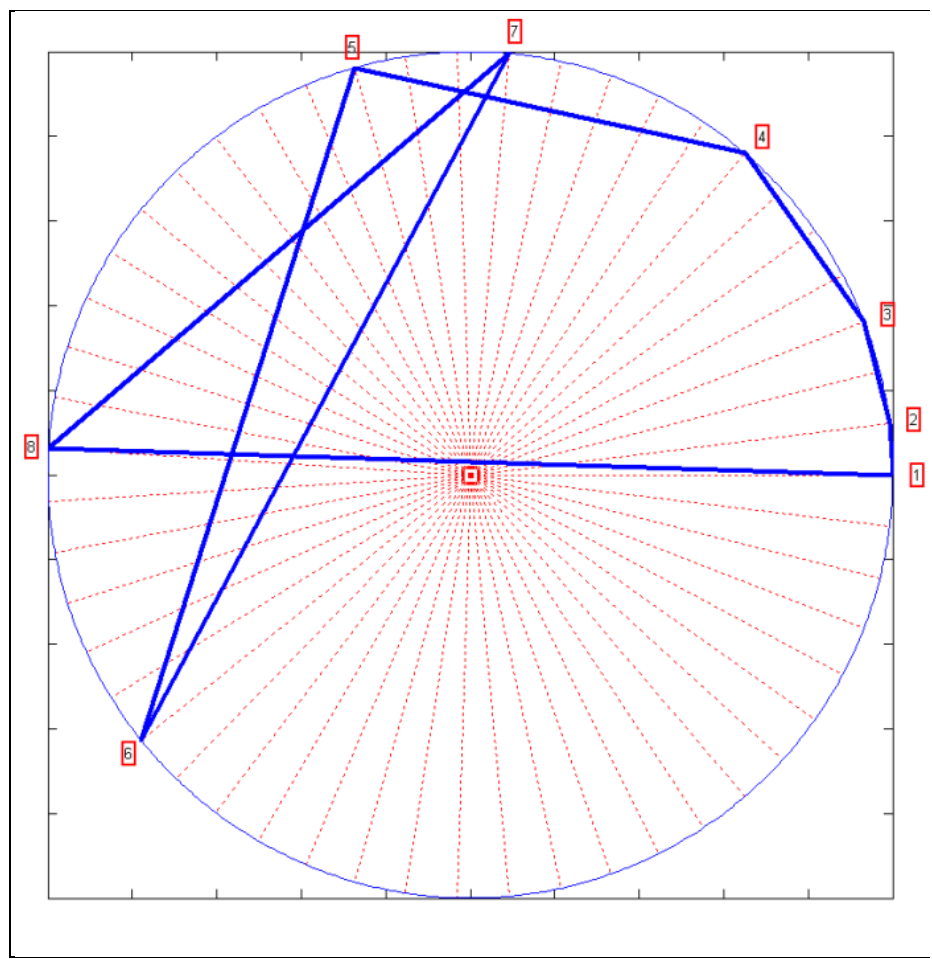

Figure 22.

Value of $2^{j}$ [51] - Each angular sector represents a equvalence class (i.e. the card position after $k$ shufflles $-k$ is boxed on the figure) - Representation of the multiplying cyclic group in $\mathrm{Z} / 51 \mathrm{Z}$ engendered by 2.

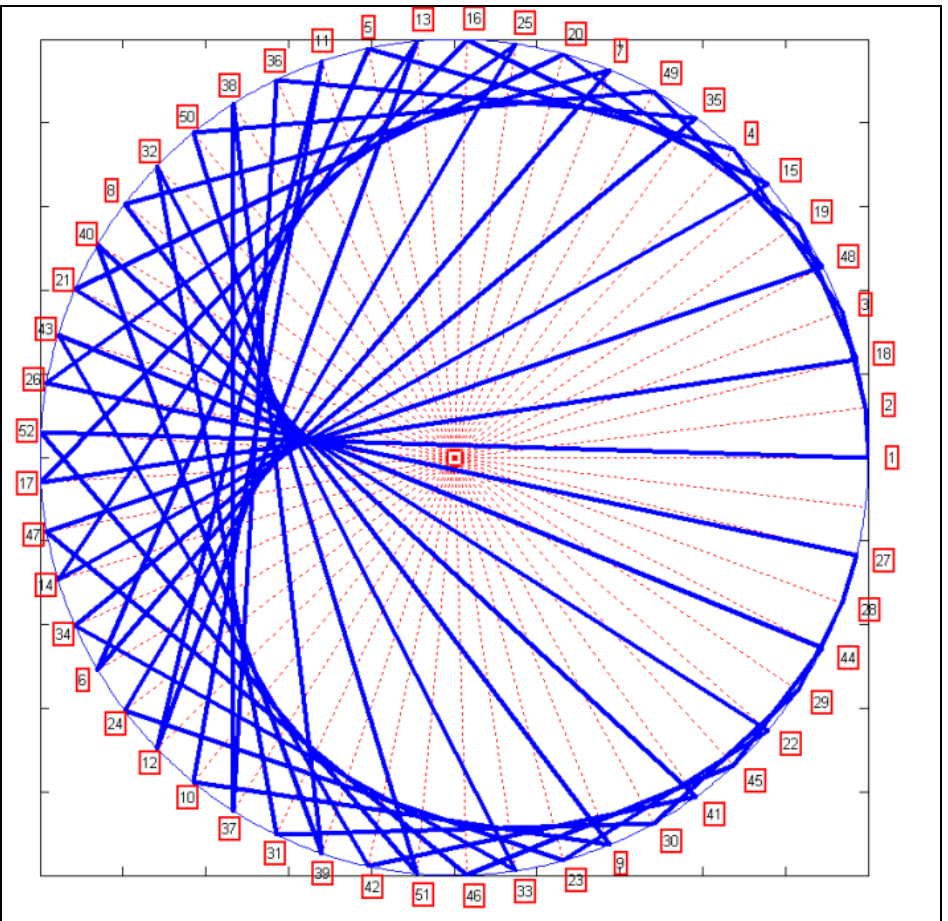

Figure 23.

Value of $2^{j}$ [53] - Each angular sector represents a equvalence class (i.e. the card posi tion after $k$ shufflles - $k$ is boxed on the figure) - Representation of the multiplying cyclic group in Z/53Z engendered by 2. 
"LEMMA 2. Let the positions in a deck of $2 \mathrm{n}$ cards be labeled $0,1, \ldots, 2 \mathrm{n}-1$. To bring the top card to position $\mathrm{k}$, express $\mathrm{k}$ in binary, interpret 0 as OUT and 1 as IN, and perform the indicated sequence of IN and OUT shuffles from left to right."' (Diaconis, 1983).

This lemma is verified on the following figures:

- the figure number 26 is for a $16=24$ card deck,

- $\quad$ the figure number 24 is for a $8=23$ card deck,

- $\quad$ the figure number 25 is for a 12 card deck.

To find the successive shuffles needed in order to bring the top card:

- in position $0=(0)_{2}$ : one OUT shuffle,

- in position $3=(11)_{2}$ : two IN shuffles,

- in position $5=(101)_{2}$ : one IN shuffle then one OUT then one IN,

in position $11=(1011)_{2}$ : an OUT shuffle then an IN one and two OUT

\section{Synthesis, Conclusion, Going Further and Prospects}

Before asking the following question "is it opportune to develop this type of teaching?', let me make a synthesis of students' work and then a conclusion in relation to my expectations. After that, I can answer the following question "is it opportune to develop this type of teaching?' by suggesting ways to go further.

\section{Synthesis and Conclusions}

Let us sum up the students' realization according to my ex pectations in Table 9. The report would completely reach my expectations and objectives if the students had searched more and found theoretical mathematical notions. The student group was more interested in the informatics part.

The students have completely achieved the MDP project but not the unsaid objectives ...

It is very interesting to note that the group did not create the asked magic trick, while they had chosen this project to learn the secrets of the magic. Eventually they got involved in the scientific work and left aside the playful aspect. This is partially due to my project management: I reminded them repeatedly that the project was at first scientific applicable to the magic.

That is why I can think that this method is efficient and practicable.

\section{Going Further and Prospects}

This kind of project could be continued by these ideas:

- Calculating how many American shuffles can be reached with an $\mathrm{N}$ card deck.

- Find relations for a $2^{\mathrm{p}}$ card deck; for example answer to this question: "Whose suit of IN and OUT Faro must have done

- to move a card from position ' $\mathrm{j}$ ' to position ' $\mathrm{k}$ ' in the card deck?”

- The answer is given by (Lachal, 2010), but it must be very interesting to give a new project in order to the students discover and prove this property.

- What leads me to think about adapting this to the whole mathematics teaching is to use magic as a method of investigation to lead students to understand the principles of mathematics and to come to love this subject.

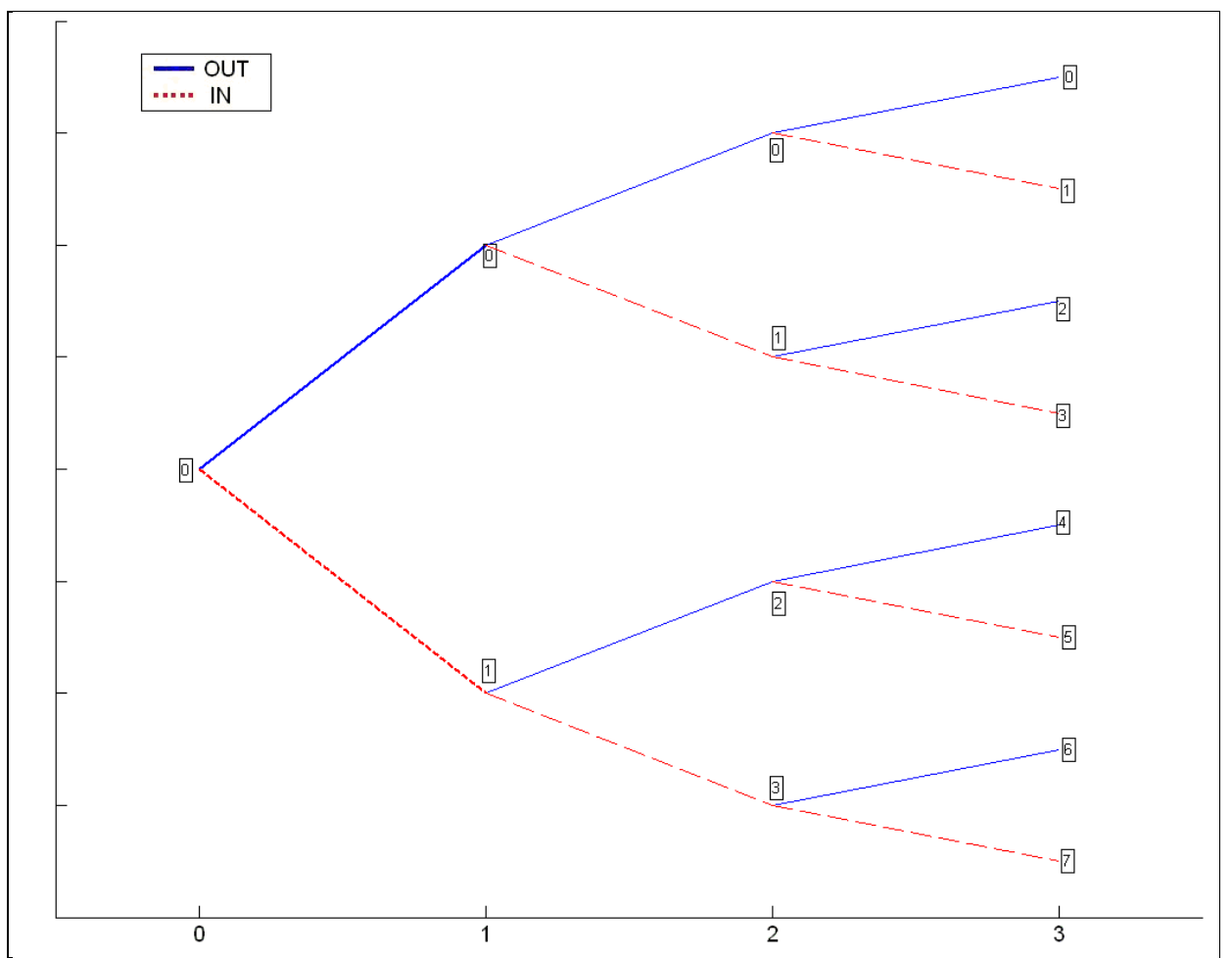

Figure 24.

Relation between the successive IN and OUT Faro shuffles to bring the top card at the position $k$ in a $8=2^{3}$ card deck. 


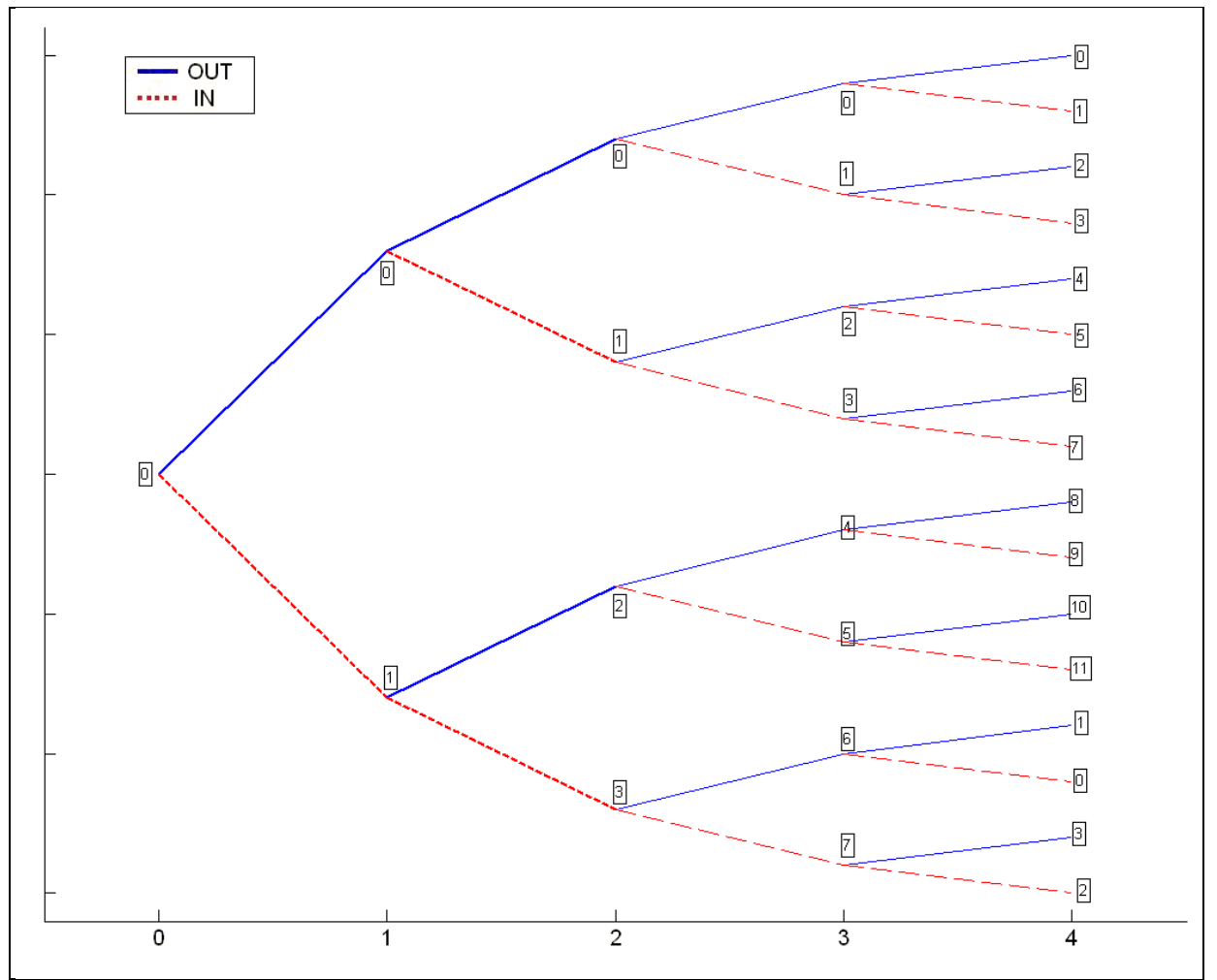

Figure 25.

Relation between the successive IN and OUT Faro shuffles to bring the top card at the position in a 12 card deck.

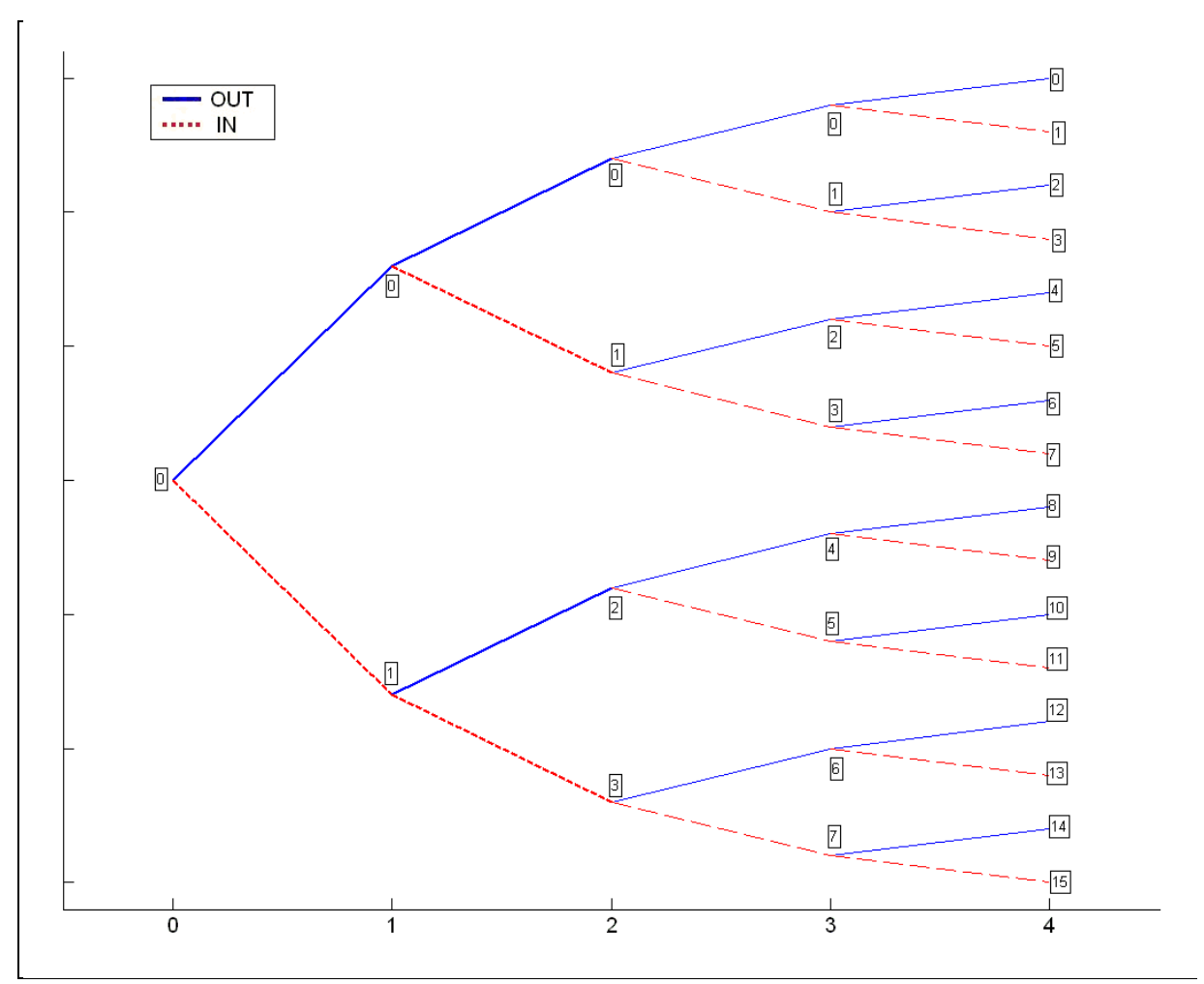

Figure 26.

Relation between the successive IN and OUT Faro shuffles to bring the top card at the position in a $16=2^{4}$ card deck. 
Table 9.

Synthesis of student work according to my expectations.

\begin{tabular}{|c|c|c|}
\hline \multirow[b]{3}{*}{$\begin{array}{l}\text { Research in } \\
\text { mathematics }\end{array}$} & Expected objectives & Students \\
\hline & Magic documentation & Good \\
\hline & $\begin{array}{l}\text { Properties of divisbility } \\
\text { Cyclic group }\end{array}$ & $\begin{array}{c}\text { Average } \\
\text { Insufficient }\end{array}$ \\
\hline \multirow{4}{*}{$\begin{array}{l}\text { Research in } \\
\text { informatics }\end{array}$} & $\begin{array}{c}\text { Programming with } \\
\text { Matlab }\end{array}$ & Very good \\
\hline & Representing with 2D & Very good \\
\hline & Modelisation & $\begin{array}{l}\text { Insufficient in mathe- } \\
\text { matics and very good for } \\
\text { computing }\end{array}$ \\
\hline & New magic card trick & Not done \\
\hline
\end{tabular}

In past, I had proposed to two groups of students a first project using the magic to make discover the optics principles (Schott, 2010). The results were different: a group having focused on the realization of the magic trick, the other one on the physical principles.

That's why I continued to propose these kinds of subjects and by a more formal follow-up, the results improved. One group even suggested to me a different (magic) subject which I reformatted to fit the P.E.S imperatives.

What leads me to think about adapting this to the whole mathematics teaching from primary school to high education (Schott, 2009) is to use magic as an investigation method to lead students to understand the mathematics principles and to come to fond of maths. I participate in the "week of the science" with primary and college classes; the results are promising.

However, magic/science parallel must be perfect and is not felt by the students as a trick. It is for it that I develop at present approaches which seem to me much more adapted than the magic:

- an informatics project: using origami for teaching the $\mathrm{C}$ language,

- an electronics project: creation of a robot playing several musical "home made" instruments in order to allow them discover the principles of waves propagation, the programming of an embarked system ...

\section{Acknowledgements}

This paper could not have been written without the encouragements of Bernard SCHOTT, my father, the invaluable help of Anne SERRIE, my mother, Claire LEROUX, the head of ARNUM, Peter WILSON and Carol MACLAREN who corrected the English. Thanks to Philippe QUOST who has read the mathematical demonstrations

\section{References}

Ammar, M. (1998). The complete cups \& balls. L\&L Publishing.

Assaf, S., Soundararajan, K., \& Diaconis, P. (2009). Riffle shuffles of a deck with repeated cards. DMTCS Proceedings, 21st International Conference on Formal Power Series and Algebraic Combinatorics, FPSAC 2009, 89-102.

Boileau, N. (1740). La scolastique. Souchay, Paris.

Chardiny, N., Dupin, B., \& Grosgeorge, S. (2010). Utiliser les mathématiques pour créer un tour de Magie utilisant le mélange FARO. Mémoire de P.S.I, ESIEA.

Diaconis, P., Graham, R. L., \& Kantor, W.M. (1983). The mathematics of perfect shuffles. Advances in Applied Mathematics, 4, 175-196. doi:10.1016/0196-8858(83)90009-X

Diaconis, P. (1998). From shuffling cards to walking around the building. An introduction to markov chain theory. Proceedings of International Congress, Berlin, I, 187-204.

Diaconis, P. (2003). Mathematical Developments from the Analysis of Riffle-Shuffling. In A. Fuanou and M. Liebeck (eds.), Groups Combinatorics and Geometry (pp. 73-97). N.J.: World Scientific.

Diaconis, P., \& Graham, R. L. (2005). The solutions to Elmsley's Problem. Mathematics magazine. doi:10.1142/9789812564481 0005

Elmsley, A. (1957). Mathématics of the weave shuffle. The Pentagram, $11,70-71$.

Erdnase, S. W. (1902). The expert at the card table. Chicago.

Gardner, M. (1958). Mathematics, magic and mystery. Dover.

Gardner, M. (2005). Martin Gardner's mathematical games : the entire collection of his scientific American columns. Mathematical Association of America.

Gilbreath, N. L. (1958). Magnetic colors. The Linking Ring, 38, 60.

Gilbreath, N. L. (1966). Second Gilbreath Principle. Linking Ring, June 1966.

Gilbreath, N. L. (March, April, May, 1989). Magic for an Audience. series of 3 articles in Genii, 52, No. 9-10-11.

Huet, G. (1991). The Gilbreath trick: A case study in axiomatisation and proof development in the Coq Proof Assistant. Proceedings, Second Workshop on Logical Frameworks, Edinburgh. doi:10.1017/CBO9780511569807

Lachal, A. (2010). Quelques mélanges parfaits de cartes. Quadrature.

Magid, A. (2005). Notices. American Mathematical Society.

Mayol, H. (2000). La Magie des cordes Maestro, HBM Production.

Mulcahy, C. (2003). Fitch Cheney's Five Card Trick. Mathematics Horizon, 10.

Mulcahy, C. (2004). Top 5 reasons to like mathematical card tricks. 11.

Mulcahy, C. (2007). An ES periment with cards. 14.

Poincaré, H. (1912). Calcul des probabilités. Rédaction de A. Quiquet. Deuxième édition, revue et augmentée par l'auteur, Gauthier-Villars, Paris.

Schott, P. (2010). The use of magic in optics in higher education. Creative Education, 1, 11-17.

Schott, P. (2009). The use of magic in mathematics: From primary school to higher education. Proceedings of ICERI2009 Conference, Madrid, Spain, 58-70.

Sheynin, O. B. (1991). H. Poincaré's work on probability. Archive for History of Exact Sciences, 42, Berlin: Springer. 


\section{Appendix A}

\section{The Objectives}

The Multi Disciplinary Project (M.D.P), workshops proposed to the $4^{\text {th }}$ semester students group activities of project type which take place throughout the winter semester (from 01/30/2010 till 05/31/2010)

Their main objective is the study of concrete applications in companies, technical-scientific matters leading to a realization or an experiment. The aspects of personal development training and of project management will have to be approached there.

They also allow developing work in a group, communication techniques as well as collaborative work.

\section{The Activities}

The students, 3 to 5 students per group, are accompanied by a teacher:

- They develop their project.

- They make an intermediate report.

- They draft a final report.

- They speak during an oral presentation.

\section{The Subjects}

The subjects are proposed by teachers of various subjects : mathematics, electronic systems, physics, scientific calculation, personal development, communication...

The proposed subjects list will be available at the office of the educational assistant and posted at the latest on December $14^{\text {th }}$, 2009.

Every domain has a limited number of subjects.

A student group can propose a subject: they have to find a teacher who wants to follow this group with their subject. Then the group must contact the educational assistant who takes care of registering the project.

\section{The Teacher}

He accompanies the student groups in their work and is in charge of the evaluation.

He assures three major meetings:

- At the beginning of activity, he advises and directs the student groups.

- During the intermediate balance report, he possibly reorientates the group and estimates the presented work.

- At the end of activity, during the oral presentation.

\section{Appendix B : 8 OUT Faro Shuffle and Nothing is done Presented with a Numbered 52 Card Deck}

Initially, the card deck is in the following order (presented on Figure 27). Each card is numbered from 1 to 52:

By cutting the deck between the cards 26 and 27 and after an OUT Faro Shuffle, the cards deck is in the following order (presented on Figure 28):

By cutting the deck between the cards 39 and 14 and after an OUT Faro Shuffle, the cards deck is in the following order (presented on Figure 29):

By cutting the deck between the cards 20 and 33 and after an OUT Faro Shuffle, the cards deck is in the following order (presented on Figure 30):

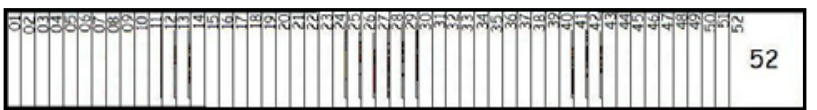

Figure 27.

A numbered card deck from 1 to 52 .

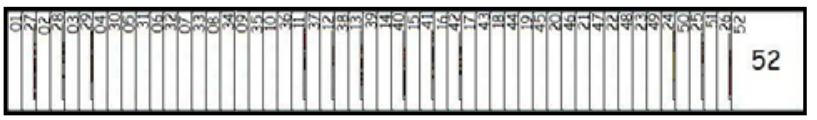

Figure 28.

A numbered card deck from 1 to 52 deck after one OUT Faro shuffle.

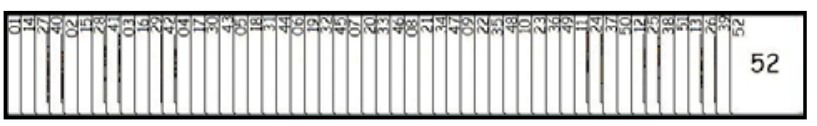

Figure 29.

A numbered card deck from 1 to 52 deck after two OUT Faro shuffle.

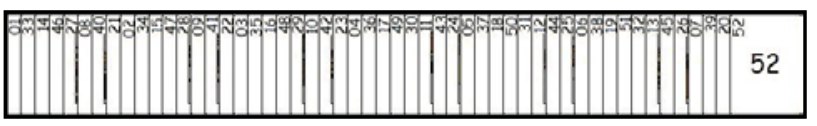

Figure 30.

A numbered card deck from 1 to 52 deck after three OUT Faro shuffle.

By cutting the deck between the cards 37 and 17 and after an OUT Faro Shuffle, the cards deck is in the following order (presented on Figure 31):

By cutting the deck between the cards 44 and 09 and after an OUT Faro Shuffle, the cards deck is in the following order (presented on Figure 32):

By cutting the deck between the cards 48 and 05 and after an OUT Faro Shuffle, the card deck is in the following order (presented on Figure 33):

By cutting the deck between the cards 50 and 03 and after an OUT Faro Shuffle, the card deck is in the following order (presented on Figure 34):

By cutting the deck between the card 51 and 02 and after an OUT Faro Shuffle, the card deck order is the initial one (presented on Figure 27).

\section{Appendix C: Informatics Matlab Program 'Faro IN' and 'Faro OUT'}

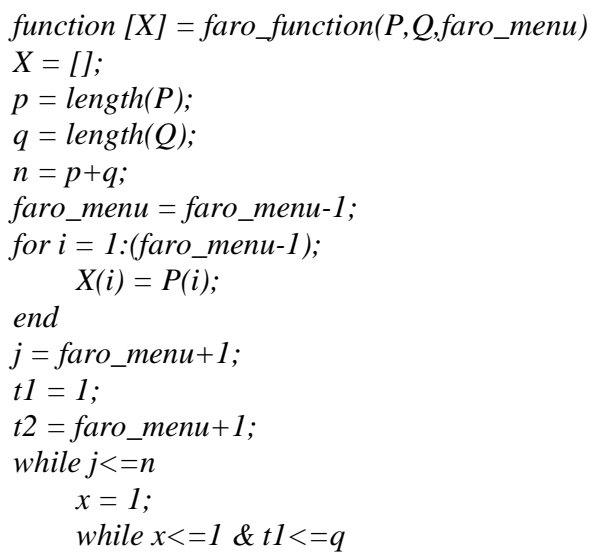



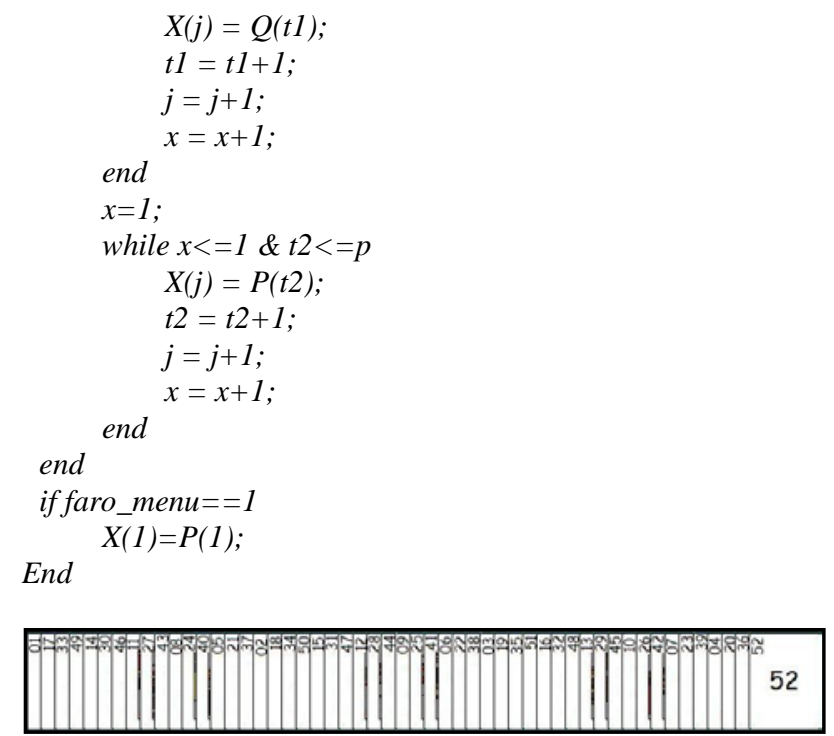

Figure 31.

A numbered card deck from 1 to 52 deck after four OUT Faro shuffle.

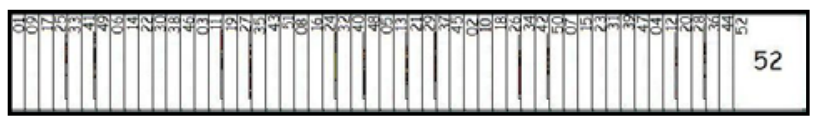

Figure 32.

A numbered card deck from 1 to 52 deck after five OUT Faro shuffle.

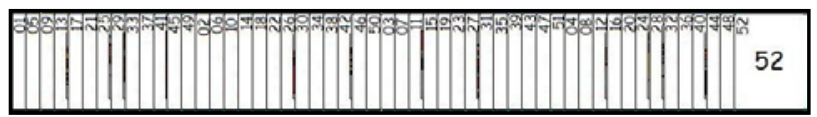

Figure 33.

A numbered card deck from 1 to 52 deck after six OUT Faro shuffle.

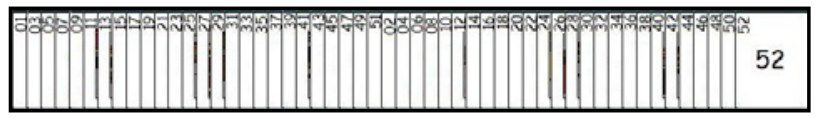

Figure 34.

A numbered card deck from 1 to 52 deck after seven OUT Faro shuffle.

Table 10 .

Position of each heart card during the 8 Out Faro shuffle.

\begin{tabular}{|c|c|c|c|c|c|c|c|c|c|c|c|c|c|}
\hline Heart & 1 & 2 & 3 & 4 & 5 & 6 & 7 & 8 & 9 & $\begin{array}{l}1 \\
0\end{array}$ & $\mathrm{~J}$ & $\mathrm{Q}$ & K \\
\hline Initial & 1 & 2 & 3 & 4 & 5 & 6 & 7 & 8 & 9 & $\begin{array}{l}1 \\
0\end{array}$ & 1 & $\begin{array}{l}1 \\
2\end{array}$ & $\begin{array}{l}1 \\
3\end{array}$ \\
\hline $\begin{array}{l}\text { Faro } \\
\text { IN } 1\end{array}$ & 1 & 3 & 5 & 7 & 9 & 1 & $\begin{array}{l}1 \\
3\end{array}$ & $\begin{array}{l}1 \\
5\end{array}$ & $\begin{array}{l}1 \\
7\end{array}$ & $\begin{array}{l}1 \\
9\end{array}$ & 2 & $\begin{array}{l}2 \\
3\end{array}$ & $\begin{array}{l}2 \\
5\end{array}$ \\
\hline Faro & & & & 1 & 1 & 2 & 2 & 2 & 3 & 3 & 4 & 4 & 4 \\
\hline IN 2 & 1 & 5 & 9 & 3 & 7 & 1 & 5 & 9 & 3 & 7 & 1 & 5 & 9 \\
\hline Faro & & & 1 & 2 & 3 & 4 & 4 & & 1 & 2 & 3 & 3 & 4 \\
\hline IN 3 & 1 & 9 & 7 & 5 & 3 & 1 & 9 & 6 & 4 & 2 & 0 & 8 & 6 \\
\hline Faro & & 1 & 3 & 4 & 1 & 3 & 4 & 1 & 2 & 4 & & 2 & 4 \\
\hline IN 4 & 1 & 7 & 3 & 9 & 4 & 0 & 6 & 1 & 7 & 3 & 8 & 4 & 0 \\
\hline Faro & 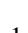 & 3 & 1 & 4 & 2 & 0 & 4 & 2 & 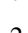 & 3 & 1 & 4 & 2 \\
\hline IN 5 & 1 & 3 & 4 & 6 & 7 & 8 & 0 & 1 & 2 & 4 & 5 & 7 & 8 \\
\hline Faro & & 1 & 2 & 4 & 2 & 1 & 2 & 4 & & 1 & 2 & 4 & \\
\hline IN 6 & 1 & 4 & 7 & 0 & 2 & 5 & 8 & 1 & 3 & 6 & 9 & 2 & 4 \\
\hline Faro & & 2 & ? & 2 & 0 & 2 & 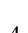 & 3 & 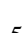 & 3 & 6 & 3 & 7 \\
\hline IN 7 & 1 & 7 & 2 & 8 & 3 & 9 & 4 & 0 & 5 & 1 & 6 & 2 & 7 \\
\hline Faro & 1 & 2 & 3 & 4 & 5 & 6 & 7 & 8 & 9 & 1 & 1 & 1 & 1 \\
\hline IN 8 & 1 & 2 & 3 & 4 & 5 & 6 & 7 & 8 & 9 & 0 & 1 & 2 & 3 \\
\hline
\end{tabular}

Table 11.

Different calculated position of the 4 of heart thanks to equation (1) and (8).

\begin{tabular}{|c|c|c|c|}
\hline & $\begin{array}{l}\text { Posi- } \\
\text { tions }\end{array}$ & $\begin{array}{c}\text { Equation (1): } \\
p_{k+1}=2 * p_{k}-1 \text { ou } \\
p_{k+1}=2 * p_{k}\end{array}$ & $\begin{array}{l}\text { Equation (8) : } \\
\mathrm{u}_{\mathrm{p}} \equiv 2^{\mathrm{m}} \mathrm{k}[2 \mathrm{p}-1]\end{array}$ \\
\hline Initial & 4 & $\mathrm{p}_{0}=4$ & $\mathrm{p}_{0}=4=>\mathrm{u}_{0}=3=\mathrm{k}$ \\
\hline Faro IN 1 & 7 & $\mathrm{p}_{1}=4 * 2-1=7$ & $\mathrm{u}_{1}=2^{1} * 3=6 \Rightarrow \mathrm{p}_{1}=7$ \\
\hline Faro IN 2 & 13 & $\mathrm{p}_{2}=7 * 2-1=13$ & $\mathrm{u}_{2}=2^{2} * 3=12=>\mathrm{p}_{2}=13$ \\
\hline Faro IN 3 & 25 & $p_{3}=13 * 2-1=25$ & 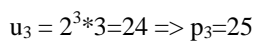 \\
\hline Faro IN 4 & 49 & $\mathrm{p}_{4}=25 * 2-1=49$ & $\mathrm{u}_{4}=2^{4} * 3=48 \Rightarrow>\mathrm{p}_{4}=49$ \\
\hline Faro IN 5 & 46 & $\mathrm{p}_{5}=49 * 2[52]=46$ & $\begin{array}{c}\mathrm{u}_{5}=2^{5 * 3}=96 \\
{[51]=45=>p_{5}=46}\end{array}$ \\
\hline Faro IN 6 & 40 & $\mathrm{p}_{6}=46 * 2[52]=40$ & $\begin{array}{c}u_{6}=2^{6} * 3=192 \\
{[51]=39=>p_{6}=40}\end{array}$ \\
\hline Faro IN 7 & 28 & $\mathrm{p}_{7}=40 * 2[52]=28$ & $\begin{array}{c}\mathrm{u}_{7}=2^{7} * 3=384 \\
{[51]=27=>\mathrm{p}_{7}=28}\end{array}$ \\
\hline Faro IN 8 & 4 & $\mathrm{p}_{8}=28 * 2[52]=4=\mathrm{p}_{0}$ & $\begin{array}{c}\mathrm{u}_{8}=2^{8} * 3=768 \\
{[51]=3=>\mathrm{p}_{8}=4}\end{array}$ \\
\hline
\end{tabular}

\section{Appendix D: 8 OUT Faro Shuffle and Nothing is Done Presented with the Different Positions of the Hearts}

The Table 10 presents the position of each heart card during the 8 OUT Faro shuffle.

For the 4 of hearts, thanks to the equations (1) and (8), their different positions are calculated:

We notice that when $\mathrm{j}$ is higher than 53 , the computer can no longer calculate $2^{\mathrm{j}} \ldots$ and we have to mix the both equations ! 